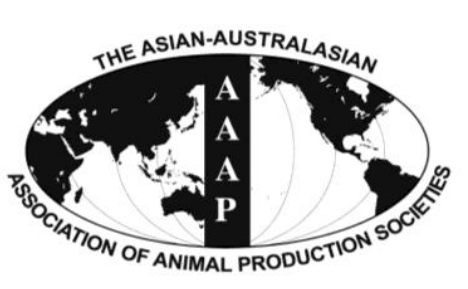

Open Access

Asian Australas. J. Anim. Sci.

Vol. 27, No. 2 : 179-186 February 2014

http://dx.doi.org/10.5713/ajas.2013.13373

www.ajas.info

pISSN 1011-2367 elSSN 1976-5517

\title{
Diversity of Butyrivibrio Group Bacteria in the Rumen of Goats and Its Response to the Supplementation of Garlic Oil
}

\author{
Zhi Zhu ${ }^{1,2}$, Suqin Hang ${ }^{1}$, Shengyong Mao ${ }^{1}$, and Weiyun $\mathrm{Zhu}^{1}{ }^{1}$ * \\ ${ }^{1}$ College of Animal Science and Technology, Nanjing Agricultural University, Nanjing 210095, China
}

\begin{abstract}
This study aimed to investigate the diversity of the Butyrivibrio group bacteria in goat rumen and its response to garlic oil (GO) supplementation as revealed by molecular analysis of cloned 16S rRNA genes. Six wethers fitted with ruminal fistulas were assigned to two groups for a cross-over design with 28-d experimental period and 14-d interval. Goats were fed a basal diet without (control) or with GO ruminal infusion $(0.8 \mathrm{~g} / \mathrm{d})$. Ruminal contents were used for DNA extraction collected before morning feeding on $\mathrm{d}$ 28. A total bacterial clone library was firstly constructed by nearly full-length $16 \mathrm{~S}$ rRNA gene cloned sequences using universal primers. The resulting plasmids selected by Butyrivibrio-specific primers were used to construct a Butyrivibrio group-specific bacterial clone library. Butyrivibrio group represented $12.98 \%$ and $10.95 \%$ of total bacteria in control and GO group, respectively. In libraries, clones were classified to the genus Pseudobutyrivibrio, Butyrivibrio and others within the family Lachnospiraceae. Additionally, some specific clones were observed in GO group, being classified to the genus Ruminococcus and others within the family Ruminococcaceae. Based on the criterion that the similarity was $97 \%$ or greater with database sequences, there were $29.73 \%$ and $18.42 \%$ of clones identified as known isolates (i.e. B. proteoclasticus and Ps. ruminis) in control and GO groups, respectively. Further clones identified as B. fibrisolvens $(5.41 \%)$ and $R$. flavefaciens $(7.89 \%)$ were specifically found in control and GO groups, respectively. The majority of clones resembled Ps. ruminis (98\% to 99\% similarity), except for Lachnospiraceae bacteria (87\% to 92\% similarity) in the two libraries. The two clone libraries also appeared different in Shannon diversity index (control 2.47 and GO group 2.91). Our results indicated that the Butyrivibrio group bacteria had a complex community with considerable unknown species in the goat rumen. (Key Words: Butyrivibrio, 16S rRNA Gene, Diversity, Garlic Oil, Goat Rumen)
\end{abstract}

\section{INTRODUCTION}

In the rumen, bacteria are largely responsible for biohydrogenation of dietary unsaturated fatty acid (FA) (Harfoot and Hazlewood, 1997). The most active bacterial species involved in the biohydrogenation of $\mathrm{C} 18$ unsaturated FA belong to the Butyrivibrio group (Paillard et al., 2007; Boeckaert et al., 2008; Durmic et al., 2008), including the genus Butyrivibrio and Pseudobutyrivibrio, and the species B. proteoclasticus (previously referred as Clostridium proteoclasticum) (Paillard et al., 2007; Moon et al., 2008). In this group, all bacteria are capable of

\footnotetext{
* Corresponding Author: Weiyun Zhu. Tel: +86-025-84395523, Fax: +86-025-84395314, E-mail: zhuweiyun@njau.edu.cn

${ }^{2}$ Department of Animal Science, Rongchang Campus, Southwest University, Chongqing 402460, China.

Submitted Jun. 30, 2013; Accepted Aug. 25, 2013; Revised Sept. 26, 2013
}

hydrogenating linoleic acid and forming cis 9 , trans11conjugated linoleic acid ( $c 9, t 11-\mathrm{CLA})$, and $t 11-\mathrm{C} 18: 1$ (TVA) as well, whereas only $B$. proteoclasticus convert TVA to C18:0 (Polan et al., 1964; Kepler et al., 1966). Nevertheless, within the complex ecosystem of rumen, there were bacteria other than B. proteoclasticus may play a predominant role in the final step of biohydrogenation (Boeckaert et al., 2008; Kim et al., 2008; Huws et al., 2010). Sequencing of bands from denaturing gradient gel electrophoresis (DGGE) also revealed that as yet uncultured bacteria classified as Prevotella, Anaerovoax (member of the Lachnospiraceae incertae sedis family), and unclassified Clostridiales and Ruminococcaceae may play a role in biohydrogenation (Huws et al., 2011). These results suggested that bacteria involved in the biohydrogenation pathway are far more complex than the previous deduced from the cultured bacteria (Polan et al., 1964; Kemp et al., 
1975; Wallace et al., 2006). This complexity is compounded by the fact that the majority of microorganisms have not yet been cultured (estimates range from $85 \%$ to $95 \%$ ) (Krause et al., 2003).

Nowadays, 16S rRNA molecular technique has become the most commonly used measure in microbial ecology (Mackie and Cann, 2005). It is reasonable to expect a culture-independent technique (e.g. 16S rRNA gene PCR) could recover more of the Butyrivibrio group fraction from the ecosystem of rumen than culture-dependent techniques. Among the molecular techniques, DGGE, one of genetic fingerprinting techniques, has its own limitation, which is relatively small fragments with length up to $500 \mathrm{bp}$ (Muyzer and Smalla, 1998). This easily leads to biases in the estimation of diversity. Complete sequences would provide more reliable phylogenetic comparison with the available database as compared with the short sequences (Stackebrandt and Goebel, 1994).

It is known that garlic (Allium sativum) oil (GO) has a wide spectrum of antibacterial activity against gramnegative and gram-positive bacteria (Reuter et al., 1996). Several gram-positive bacteria are involved in biohydrogenation of unsaturated FA in the rumen (Harfoot and Hazlewood, 1997). This attracted our interest in whether GO could affect the diversity of the Butyrivibrio group bacteria in the rumen. Therefore, the present study, using sequence analysis of nearly full-length $16 \mathrm{~S}$ rRNA gene clones, aimed to investigate the diversity of the Butyrivibrio group bacteria and its response to GO supplementation in the rumen of goats.

\section{MATERIALS AND METHODS}

\section{Animals, experimental design, and diets}

Six local crossbred wethers fitted with ruminal fistulas (19.3 $\pm 1.2 \mathrm{~kg}$ body weight $[\mathrm{BW}]$, mean \pm standard deviation) were assigned to two groups for a cross-over design with 28-d experimental period and 14-d interval. Goats were fed a basal diet without (control) or with GO infusion via ruminal fistula. The dose $0.04 \mathrm{~g} / \mathrm{kg} \mathrm{BW}$ was used in the present study according to the dose of GO in lamb research $(0.01 \mathrm{~g} / \mathrm{kg} \mathrm{BW})$ (Chaves et al., 2008) and our previous study in dairy goats $(0.01,0.02$, and $0.03 \mathrm{~g} / \mathrm{kg} \mathrm{BW}$ ) (Zhu et al., 2013). Accordingly, the dose was $0.8 \mathrm{~g} / \mathrm{d}$. The basal diet was formulated according to Feeding Standard of Meatproducing Sheep and Goats (NY/Y 816-2004; Ministry of Agriculture, China, 2004) in order to fulfill the maintenance requirements of goats. Diets consisted of grass hay (Leymus chinensis, $0.38 \mathrm{~kg} / \mathrm{d}$ dry matter (DM)) and concentrate (corn meal-soybean meal-wheat bran, $0.22 \mathrm{~kg} / \mathrm{d} \mathrm{DM}$ ), and were fed separately. The chemical analysis of diets has been published in our previous report (Zhu et al., 2012). Garlic oil product was infused into rumen using a 1-mL syringe via ruminal fistulas immediately after the delivery of concentrate to animal. For each goat, the infusing lasted a few seconds. Hay was offered after the concentrate was ingested by the goats. Both diet and GO infusion were offered in equal portions at 08:00 and 18:00 h. No refusals of concentrate and no statistical difference of hay intake $(0.33 \mathrm{~kg} / \mathrm{d}$ for control and $0.32 \mathrm{~kg} / \mathrm{d}$ for GO group) were observed in two groups. The main components of GO (stored at $4^{\circ} \mathrm{C}$; Henan Yuanhua Biotechnology Co., Ltd., China) were sulfur compounds, such as the predominant diallyl trisulfide $(29.3 \%)$ and diallyl disulfide $(31.3 \%)$. The remaining $40 \%$ components of GO were other sulfur compounds. All goats had free access to fresh water throughout the experiment. Goats were fed individually in pens and managed in accordance with guidelines regarding animal care provided by College of Animal Science and Technology, Nanjing Agricultural University.

\section{Sampling, DNA extraction, and PCR amplification}

Ruminal contents from multiple sites within the rumen were collected via ruminal fistula before morning feeding on d 28 of each period. Sample collection was performed with a suction device which could ensure the same ratio of liquid to solid in ruminal contents across animals. Samples were subsequently stored at $-25^{\circ} \mathrm{C}$ for latter DNA extraction. Prior to DNA extraction, samples were thawed and then homogenized using the Ultra Turrax T25 homogenizer (IKA Werke Labortechnik, Staufen, Germany). Total DNA was extracted from $1.5 \mathrm{~mL}$ homogenized ruminal contents by bead-beating for 3 min using a mini-bead beater (Biospec Products, USA), followed by phenol-chloroform extraction (Zoetendal et al., 1998). DNA was then precipitated with ethanol and pellet was resuspended in $70 \mu \mathrm{L}$ Tris$\mathrm{HCl} /$ EDTA buffer. Thereafter, DNA was stored at $-25^{\circ} \mathrm{C}$ for latter PCR amplification.

Bacterial 16S rRNA gene sequence of each sample was amplified on an Eppendorf Mastercycler Gradient (Eppendorf, Germany) with universal primers, forward $8 \mathrm{f}$ (5'-AGA GTT TGA TCC TGG CTC AG-3') and reverse 1510r (5'-GGC TAC CTT GTT ACG A-3') (Ding and Yokota, 2004). A reaction mixture $(50 \mu \mathrm{L})$ consisted of 1 $\mu \mathrm{L}$ DNA extract, $1 \mu \mathrm{L}$ of each primer $(10 \mu \mathrm{mol} / \mathrm{L}), 1 \mu \mathrm{L}$ deoxynucleotide triphosphate mixture (10 mmol/L each), 5 $\mu \mathrm{L} \mathrm{10 \times} \mathrm{PCR} \mathrm{buffer,} 6 \mu \mathrm{L} \mathrm{MgCl}_{2}(25 \mathrm{mmol} / \mathrm{L}), 0.25 \mu \mathrm{L}$ Taq polymerase $(5 \mathrm{U} / \mu \mathrm{L})$ and lastly $34.75 \mu \mathrm{L}$ PCR-grade $\mathrm{H}_{2} \mathrm{O}$. The PCR was performed under the following conditions: one cycle of $94^{\circ} \mathrm{C}$ for $3 \mathrm{~min}$ for denaturation, followed by 30 cycles of $94^{\circ} \mathrm{C}$ for $30 \mathrm{~s}$ for denaturation, $57^{\circ} \mathrm{C}$ for $30 \mathrm{~s}$ for annealing, and $68^{\circ} \mathrm{C}$ for $1.5 \mathrm{~min}$ for extension, and final extension at $68^{\circ} \mathrm{C}$ for $7 \mathrm{~min}$. Amplicons were measured in 
triplicate using a NanoDrop-1000 spectrophotometer (Labtech International, UK), and analyzed by electrophoresis on a $1.5 \%$ agarose gel $(w / v)$ to check its size.

\section{Construction of clone library}

According to the method from Pei et al. (2010), equal quantities of PCR products of six samples in each experimental group were mixed together for clone library construction. The mixture was purified by kit (Invitrogen, China) and then cloned into Escherichia coli strain TOP10 (Tiangen Biotech, China) using pGEM-T Easy vector (Promega, USA). Transformants from each library were randomly picked up. Recombinant plasmids were extracted by lysis $\left(95^{\circ} \mathrm{C}\right.$ for $\left.15 \mathrm{~min}\right)$. All plasmids were checked by amplification with pGEM-T-specific primers Sp6 (forward, 5'-ATT TAG GTG ACA CTA TAG-3') and T7 (reverse, 5'AAT ACG ACT CAC TAT AGG-3'). PCR reaction mixtures of primers Sp6 and $\mathrm{T} 7$ were the same to that of primers $8 \mathrm{f}$ and 1510r. PCR amplification was carried out with an initial DNA denaturation step at $94^{\circ} \mathrm{C}$ for $3 \mathrm{~min}$, followed by 34 cycles of denaturation at $94^{\circ} \mathrm{C}$ for $30 \mathrm{~s}$, annealing at $55^{\circ} \mathrm{C}$ for $30 \mathrm{~s}$, and extension at $68^{\circ} \mathrm{C}$ for $1.5 \mathrm{~min}$, and final extension at $68^{\circ} \mathrm{C}$ for $7 \mathrm{~min}$. The plasmids containing an insert approx. $1.5 \mathrm{kbp}$ based on the DNA marker ladder run on the same gel were used to construct a total bacterial clone library.

Butyrivibrio group bacterial library was constructed with the plasmids selected from the total bacterial library by PCR amplification using Butyrivibrio-specific forward primer B395f (5'-GYG AAG AAG TAT TTC GGT AT-3') and reverse primer B812r (5'-CCA ACA CCT AGT ATT CAT C-3') (Boeckaert et al., 2008). PCR reaction mixtures of primers B395f and B812r were the same to that of primers $8 \mathrm{f}$ and $1510 \mathrm{r}$. The amplification conditions were as follows: $94^{\circ} \mathrm{C}$ for $5 \mathrm{~min}, 34$ cycles of $94^{\circ} \mathrm{C}$ for $30 \mathrm{~s}, 55^{\circ} \mathrm{C}$ for $30 \mathrm{~s}$ and $72^{\circ} \mathrm{C}$ for $40 \mathrm{~s}$, and a final extension of $72^{\circ} \mathrm{C}$ for $7 \mathrm{~min}$. The amplicons were checked on a $1.5 \%$ agarose gel $(w / v)$. Then the plasmids amplified by the specific primers were sequenced in both directions commercially (Beijing Genomics Institute, China).

\section{Sequence analysis, diversity estimation, and phylogenetic analysis}

All chimeric sequences were discarded before submitting to GenBank database. Classification analysis of sequence was conducted by comparison with Ribosomal Database Project (RDP) database. Similarity searches were performed with BLAST tool in GenBank database. The proportion of the Butyrivibrio group bacteria in total bacteria was expressed by the ratio of the number of clones selected by Butyrivibrio-primers to the number of clones in the total bacterial library. The proportion of each kind of clone (according to the nearest known relative and the similarity) in the Butyrivibrio group bacterial library was calculated as follows: the number of that clone type divided by the total clone numbers of this library.

The Shannon-Weaver diversity index $\left(H_{\text {shannon }}\right)$ was calculated for each library with the DOTUR program (Schloss and Handelsman, 2005) to characterize the diversity of the Butyrivibrio group bacteria.

Sequences were aligned using Clustalx1.83, and a phylogenetic tree was constructed by Neighbor-Joining of Bootstrap Test in MEGA4 software. Percentage bootstrap values were calculated from 1,000 replicates and were shown at nodes if $\geq 50 \%$.

\section{Nucleotide sequence accession numbers}

The 16S rRNA gene sequences of clones reported in this paper have been deposited in GenBank database under accession numbers HQ326588 to HQ326624 (control) and JN008400 to JN008437 (GO).

\section{RESULTS}

\section{Sequence analysis}

Total bacterial library consisted of 285 and 347 clones in control and GO groups, in which 37 and 38 clones were selected by Butyrivibrio-specific primers and constructed as the Butyrivibrio group bacterial library, respectively. Accordingly, the Butyrivibrio group represented $12.98 \%$ (control) and $10.95 \%(\mathrm{GO})$ of total bacteria in the rumen. In both libraries, clones were classified to the genus Pseudobutyrivibrio, Butyrivibrio and others within the family Lachnospiraceae based on comparisons with RDP database. Some clones only observed in GO group were classified to the genus Ruminococcus and others within the family Ruminococcaceae.

Using the criterion that the similarity was $97 \%$ or greater with database sequences, $29.73 \%$ and $18.42 \%$ of clones were identified as known isolates (B. proteoclasticus and Ps. ruminis) in control and GO groups, respectively (Table 1). The majority of clones resembled Ps. ruminis with similarity ranging from $98 \%$ to $99 \%$, except for Lachnospiraceae bacterium (similarities from $87 \%$ to $92 \%$ ) in the two libraries. In addition to B. proteoclasticus and Ps. ruminis in both libraries, clones identified as $B$. fibrisolvens $(5.41 \%)$ and $R$. flavefaciens $(7.89 \%)$ were specifically observed in control and GO groups, respectively. Accordingly, B. fibrisolvens and $R$. flavefaciens accounted for $0.70 \%$ and $0.86 \%$ of total bacteria, respectively.

The Shannon index (a diversity index that accounts for both abundance and evenness of the species present in the community) of control and GO group libraries were 2.47 and 2.91 , respectively. 
Table 1. 16S rRNA gene clones of the Butyrivibrio group bacteria from goat rumen

\begin{tabular}{|c|c|c|c|c|c|}
\hline \multicolumn{2}{|l|}{ Nearest known relative } & \multirow{2}{*}{ Library } & \multirow{2}{*}{ Size of clone (bp) } & \multirow{2}{*}{ No. of clone } & \multirow{2}{*}{ Proportion $(\%)$} \\
\hline Name & Similarity $(\%)$ & & & & \\
\hline \multirow[t]{2}{*}{ Butyrivibrio proteoclasticus } & $97.2-98.6$ & Control & $1,505-1,506$ & 3 & 8.11 \\
\hline & 98.7 & Garlic oil & 1,506 & 1 & 2.63 \\
\hline \multirow[t]{2}{*}{ Pseudobutyrivibrio ruminis } & $98.5-99.2$ & Control & $1,489-1,494$ & 8 & 21.62 \\
\hline & $98.0-99.3$ & Garlic oil & $1,492-1493$ & 6 & 15.79 \\
\hline Butyrivibrio fibrisolvens & $99.2,99.5$ & Control & $1,491,1,493$ & 2 & 5.41 \\
\hline Ruminococcus flavefaciens & $98.1-99.1$ & Garlic oil & $1,474-1,475$ & 3 & 7.89 \\
\hline \multicolumn{6}{|l|}{ Unidentified $^{a}$} \\
\hline \multirow[t]{2}{*}{ Butyrivibrio hungatei } & 89.4 & Control & 1,491 & 1 & 2.70 \\
\hline & 89.0 & Garlic oil & 1,493 & 1 & 2.63 \\
\hline \multirow[t]{2}{*}{ Butyrivibrio proteoclasticus } & $89.4,91.6$ & Control & $1,495,1,503$ & 2 & 5.41 \\
\hline & 92.1 & Garlic oil & 1,508 & 1 & 2.63 \\
\hline \multirow[t]{2}{*}{ Clostridiaceae bacterium } & $85.8-90.2$ & Control & $1,483-1,500$ & 3 & 8.11 \\
\hline & $84.7,90.6$ & Garlic oil & $1,483,1,488$ & 2 & 5.26 \\
\hline \multirow[t]{2}{*}{ Eubacterium oxidoreducens } & $92.1,92.3$ & Control & $1,509,1,511$ & 2 & 5.41 \\
\hline & $91.0,93.6$ & Garlic oil & $1,493,1,509$ & 2 & 5.26 \\
\hline \multirow[t]{2}{*}{ Eubacterium ruminantium } & $90.3,92.5$ & Control & $1,491,1,507$ & 2 & 5.41 \\
\hline & $94.2,94.2$ & Garlic oil & 1,504 & 2 & 5.26 \\
\hline \multirow[t]{2}{*}{ Lachnospiraceae bacterium } & $87.3-88.8$ & Control & $1,470-1,476$ & 12 & 32.43 \\
\hline & $88.1-92.0$ & Garlic oil & $1,473-1,492$ & 8 & 21.05 \\
\hline Clostridium phytofermentans & 92.0 & Control & 1,482 & 1 & 2.70 \\
\hline Clostridium saccharolyticum & 92.0 & Control & 1,478 & 1 & 2.70 \\
\hline Clostridium sp. & $89.0-91.0$ & Garlic oil & $1,493-1,506$ & 3 & 7.89 \\
\hline Clostridiales bacterium & $92.2,94.2$ & Garlic oil & $1,485,1,530$ & 2 & 5.26 \\
\hline Eubacterium contortum & 91.0 & Garlic oil & 1,511 & 1 & 2.63 \\
\hline Eubacterium coprostanoligenes & 90.6 & Garlic oil & 1,490 & 1 & 2.63 \\
\hline Eubacterium ventriosum & $94.2,94.3$ & Garlic oil & 1,512 & 2 & 5.26 \\
\hline Papillibacter cinnamivorans & $86.6,90.0$ & Garlic oil & $1,475,1,497$ & 2 & 5.26 \\
\hline Ruminococcus flavefaciens & 93.7 & Garlic oil & 1,473 & 1 & 2.63 \\
\hline
\end{tabular}

${ }^{\text {a }}$ Similarity is less than $97 \%$.

\section{Phylogenetic analysis}

In a phylogenetic tree, a tight and unique cluster (Pseudobutyrivibrio) was formed by clones resembling Ps. ruminis and $B$. fibrisolvens, in which all the sequences were classified to the genus Pseudobutyrivibrio (Figure 1). The majority of clones classified to the genus within the family Lachnospiraceae formed many clusters, which were genetically distinct from clusters of Pseudobutyrivibrio and Butyrivibrio. In addition, some Butyrivibrio bacterial clones found in the GO group clustered closely with $R$. flavefaciens and uncultured Ruminococcaceae bacterium.

\section{DISCUSSION}

In this study, the Butyrivibrio group bacteria represented $12.98 \%$ of total bacteria in the rumen of goats. This result was in line with the previous report with respect to the genus Butyrivibrio isolates which accounted for $10 \%$ to $30 \%$ of total culturable bacteria in the rumen (Kopečný et al., 2003; Jarvis and Moore, 2010). The proportion of the Butyrivibrio group in total bacteria tended to be reduced as
GO supplementation in the rumen. This effect may be due to the wide spectrum of antibacterial activity of GO (Reuter et al., 1996), which consequently leads to changes in the number of bacteria.

This study revealed that the Butyrivibrio group bacteria are complex with considerable unknown species in goat rumen. In addition to the genus Pseudobutyrivibrio, Butyrivibrio and others within the family Lachnospiraceae in both libraries, some clones classified to the genus Ruminococcus and others within the family Ruminococcaceae were specifically found in the GO group. The family Lachnospiraceae includes the genus Butyrivibrio, Lachnospira and Roseburia (Cotta and Forster, 2006). Butyrivibrio isolates have high genetic diversity (Kopečný et al., 2003), in which the roles of B. fibrisolvens and $B$. proteoclasticus in biohydrogenation were investigated widely (Jenkins et al., 2008). Previous study found the concomitant disappearance of unknown Lachnospiraceae strains and a decrease in ruminal C18:0 concentration, suggesting that these unknown bacteria might play a role in in vivo C18:0 production (Boeckaert et al., 2008). However, 


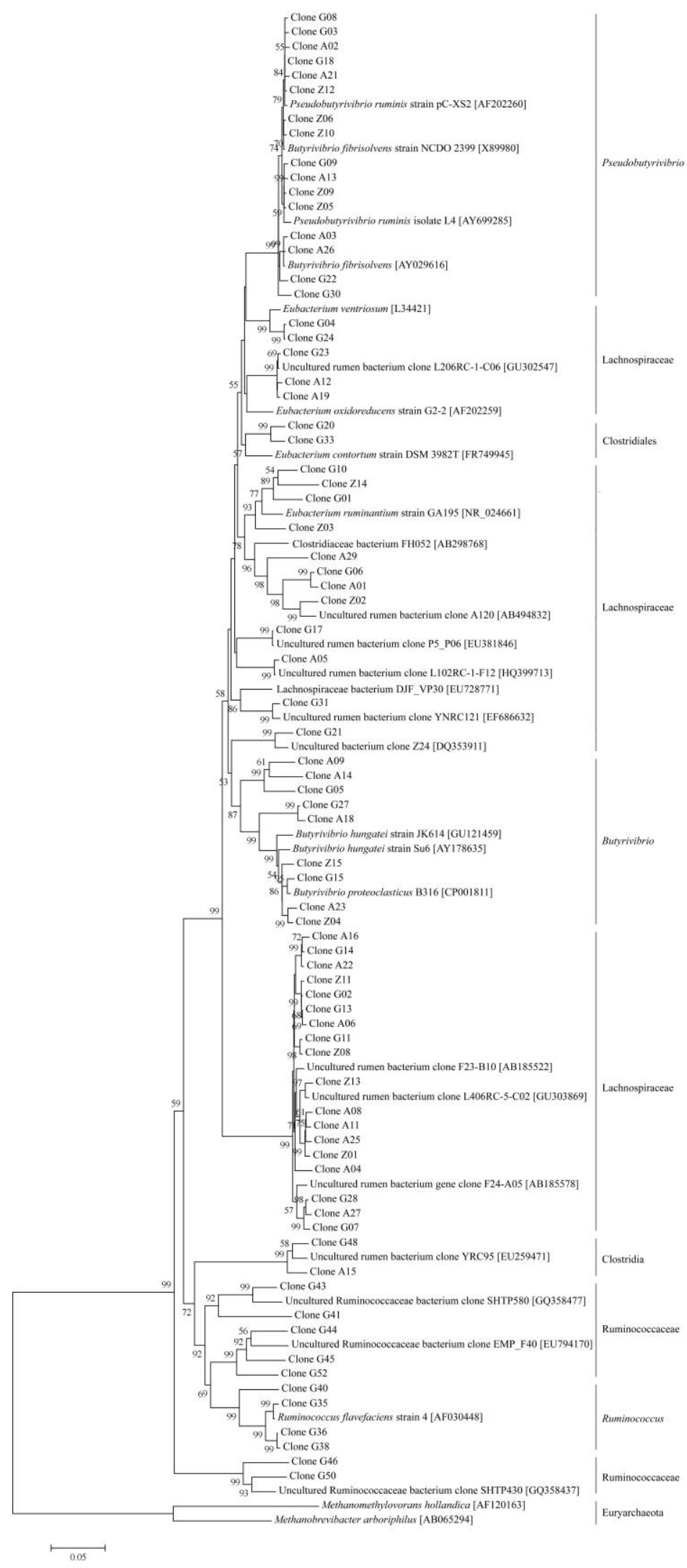

Figure 1. Phylogenetic tree of the Butyrivibrio group bacterial 16S rRNA gene clones from goat rumen. Clone A and clone $\mathrm{Z}$ are from control (HQ326588 to HQ326624), clone G (JN008400 to JN008437) are from goats treated by garlic oil infusion (0.8 g/d) via ruminal fistula. GenBank accession numbers of the known bacteria are shown in brackets. The bar represents $1 \mathrm{nt}$ substitution per $100 \mathrm{nt}$. 
putative taxonomic identification of terminal restriction fragments revealed that uncultured bacteria including those belonging to unclassified Lachnospiraceae were likely associated with TVA and $c 9, t 11$-CLA production (Huws et al., 2011). Ruminococcus has been implicated in biohydrogenation in the rumen as reviewed by Durmic et al. (2008). Additionally, recent research showed that the unclassified Ruminococcaceae, as shown by DGGE sequences, associated not only with the ruminal concentrations of TVA, $c 9, t 11$-CLA, but also with C18:0 (Huws et al., 2011). In the present phylogenetic tree, clones classified to the genus Ruminococcus and others within the family Ruminococcaceae and Lachnospiraceae formed genetically distinct clusters, indicating that their roles in biohydrogenation may be different from the genus Pseudobutyrivibrio and Butyrivibrio. However, to our knowledge, the actual roles of bacteria belonging to the genus Ruminococcus and others within the family Ruminococcaceae and Lachnospiraceae are not determined and need further investigation. Meanwhile, the vast majority of clone sequences had low similarity (<97\%) with the closest known isolates in both libraries, suggesting that there were many yet unknown species within the Butyrivibrio group. The majority of microorganisms in the rumen have not been cultured (estimates range from $85 \%$ to 95\%) (Krause et al., 2003). This partly explains the low similarity of cloned sequences with the known isolates in the present study.

In the complex community, the majority of clones resembled the known isolate $P$ s. ruminis with $\geq 97 \%$ similarity in the Butyrivibrio group bacterial library. To our knowledge, Van Gylswyk et al. (1996) for the first time investigated the feature of $P$ s. ruminis from the rumen, and reported that Ps. ruminis differed sufficiently from the genus Butyrivibrio and was placed in a new genus. Ps. ruminis closely resembles $B$. fibrisolvens in many phenotypical characteristics (Van Gylswyk et al., 1996). Presently, clones closely resembling Ps. ruminis and $B$. fibrisolvens formed a tight and unique cluster (Pseudobutyrivibrio) in the phylogenetic tree, in which all the sequences were classified to the genus Pseudobutyrivibrio. Ps. ruminis may have a role similar to B. fibrisolvens in biohydrogenation. Nonetheless, there were differences between them. Ps. ruminis contains high medium chain FA (C12 to $\mathrm{C} 15)$, whereas $B$. fibrisolvens contains high cellular compositions of long chain FA (C16 to C18) (Van Gylswyk et al., 1996; Kopečný et al., 2003). Afterwards, Ps. ruminis was reported to have high isomerase activity which converts the cis-12 bonds of linoleic acid $(c 9, c 12$-CLA) to trans-11 bonds (Koppová et al., 2006). Therefore, species resembling Ps. ruminis may contribute to the accumulation of $c 9, t 11-C L A$ in the rumen. In addition, $B$. fibrisolvens is capable of hydrogenating linoleic acid and forming $c 9, t 11$-CLA, and TVA as well (Polan et al., 1964; Kepler et al., 1966). Considering the higher proportion of Ps. ruminis in the libraries, Ps. ruminis may play a more important role than $B$. fibrisolvens in the biohydrogenation of linoleic acid to $c 9, t 11$-CLA.

The diversity of the Butyrivibrio group bacteria was modified by GO supplementation in the rumen as revealed by Shannon index. The reason behind this was not very clear. A previous report showed that high concentration (312 mg/L of culture fluid) of GO did not have detrimental effects on rumen microbial fermentation in a continuous culture trial $(8 \mathrm{~d})$, in contrast with the effects observed in a batch fermentation trial (24 h) (Busquet et al., 2005). Busquet et al. (2005) suggested that after longer adaptation, the microbial population inhibited by GO could be replaced by other resistant bacterial groups. This replacement might lead to modification of the Butyrivibrio group bacterial community.

Among the composition of bacteria, specific appearances of $B$. fibrisolvens and $R$. flavefaciens were observed in control and GO groups, respectively. $R$. flavefaciens is one of the most predominant fibrolytic bacteria in the rumen (Hespell et al., 1997). In the future, it is important to verify the roles of $R$. flavefaciens in the biohydrogenation in rumen. In the present study, the bacterial species $(>97 \%$ similarity) resembling $B$. fibrisolvens and $R$. flavefaciens accounted for $0.70 \%$ and $0.86 \%$, respectively, of total bacteria in goat rumen. A previous report showed that the proportion of $16 \mathrm{~S}$ rRNA gene copies attributable to $B$. fibrisolvens and $R$. flavefaciens were $<0.03 \%$ and $0.5 \%$ to $1 \%$, respectively, of the total bacteria from the rumen of lactating cows, as investigated by relative quantification real-time PCR (Stevenson and Weimer, 2007). In addition to animal species, diets and methodology used were the possible reasons that caused this discrepancy in the proportion of B. fibrisolvens in total ruminal bacteria between the two experiments. The low proportion of $B$. fibrisolvens in the rumen as reported by Stevenson and Weimer (2007) may lead to its unlikely selection from plasmids in the total bacterial library. Owing to the antibacterial activity (Reuter et al., 1996), the possible inhibition of GO on B. fibrisolvens may also partly illustrate the disappearance of B. fibrisolvens in GO group library. For the lack of appearance of $R$. flavefaciens in control library, the report that bacteriocins produced by $B$. fibrisolvens inhibited ruminococci growth (Krause et al., 1999) may in part explain this phenomenon.

In conclusion, this study revealed that the Butyrivibrio group represented $12.98 \%$ of total bacteria the rumen of goats. Many unique unknown bacterial sequences were found in the Butyrivibrio group bacterial library. Nevertheless, the roles of these unknown bacteria need 
further investigation.

\section{ACKNOWLEDGEMENTS}

This work was supported by a grant from the Natural Science Foundation of Jiangsu Province (BK2007721).

\section{REFERENCES}

Boeckaert, C., B. Vlaeminck, V. Fievez, L. Maignien, J. Dijkstra and N. Boon. 2008. Accumulation of trans $\mathrm{C}_{18: 1}$ fatty acids in the rumen after dietary algal supplementation is associated with changes in the Butyrivibrio community. Appl. Environ. Microbiol. 74:6923-6930.

Busquet, M., S. Calsamiglia, A. Ferret, M. D. Carro, and C. Kamel. 2005. Effect of garlic oil and four of its compounds on rumen microbial fermentation. J. Dairy Sci. 88:4393-4404.

Chaves, A. V., K. Stanford, M. E. R. Dugan, L. L. Gibson, T. A. McAllister, F. Van Herk, and C. Benchaar. 2008. Effects of cinnamaldehyde, garlic and juniper berry essential oils on rumen fermentation, blood metabolites, growth performance, and carcass characteristics of growing lambs. Livest. Sci. 117:215-224.

Cotta, M. and R. Forster. 2006. The family Lachnospiraceae, including the genera Butyrivibrio, Lachnospira and Roseburia. In: The prokaryotes: a handbook on the biology of bacteria (Ed. M. Dworkin, S. Falkow, E. Rosenberg, K. H. Schleifer and E. Stackebrandt). Springer, New York. pp. 1002-1021.

Ding, L. and A. Yokota. 2004. Proposals of Curvibacter gracilis gen. nov., sp. nov. and Herbaspirillum putei sp. nov. for bacterial strains isolated from well water and reclassification of [Pseudomonas] huttiensis, [Pseudomonas] lanceolata, [Aquaspirillum] delicatum and [Aquaspirillum] autotrophicum as Herbaspirillum huttiense comb. nov., Curvibacter lanceolatus comb. nov., Curvibacter delicatus comb. nov. and Herbaspirillum autotrophicum comb. nov.. Int. J. Syst. Evol. Microbiol. 54:2223-2230.

Durmic, Z., C. S. McSweeney, G. W. Kemp, P. Hutton, R. J. Wallace, and P. E. Vercoe. 2008. Australian plants with potential to inhibit bacteria and processes involved in ruminal biohydrogenation of fatty acids. Anim. Feed Sci. Technol. 145:271-284.

Harfoot, C. G. and G. P. Hazlewood. 1997. Lipid metabolism in the rumen. In: The Rumen Microbial Ecosystem, 2nd Ed. (Ed. P. N. Hobson and C. S. Stewart). Chapman \& Hall, London. pp. 382-426.

Hespell, R. B., D. E. Akin, and B. A. Dehority. 1997. Bacteria, fungi, and protozoa of the rumen. In: Gastrointestinal Microbiology, 2nd Ed. (Ed. R. I. Mackie, B. A. White, and R. E. Isaacson). Chapman \& Hall, New York. pp. 59-141.

Huws, S. A., M. R. F. Lee, S. M. Muetzel, M. B. Scott, R. J. Wallace, and N. D. Scollan. 2010. Forage type and fish oil cause shifts in rumen bacterial diversity. FEMS Microbiol. Ecol. 73:396-407.

Huws, S. A., E. J. Kim, M. R. F. Lee, M. B. Scott, J. K. S. Tweed, E. Pinloche, R. J. Wallace, and N. D. Scollan. 2011. As yet uncultured bacteria phylogenetically classified as Prevotella, Lachnospiraceae incertae sedis and unclassified Bacteroidales,
Clostridiales and Ruminococcaceae may play a predominant role in ruminal biohydrogenation. Environ. Microbiol. 13:1500-1512.

Jarvis, G. N. and E. R. B. Moore. 2010. Lipid metabolism and the rumen microbial ecosystem. In: Handbook of Hydrocarbon and Lipid Microbiology (Ed. K. N. Timmis). Springer, Berlin Heidelberg. pp. 2245-2257.

Kemp, P., R. White, and D. Lander. 1975. The hydrogenation of unsaturated fatty acids by five bacterial isolates from the sheep rumen, including a new species. J. Gen. Microbiol. 90:100-114.

Kepler, C. R., K. P. Hirons, J. J. McNeill, and S. B. Tove. 1966. Intermediates and products of the biohydrogenation of linoleic acid by Butyrivibrio fibrisolvens. J. Biol. Chem. 241:13501354.

Kim, E. J., S. A. Huws, M. R. F. Lee, J. D. Wood, S. M. Muetzel, R. J. Wallace, and N. D. Scollan. 2008. Fish oil increases the duodenal flow of long chain polyunsaturated fatty acids and trans-11 18:1 and decreases 18:0 in steers via changes in the rumen bacterial community. J. Nutr. 138:889-896.

Kopečný, J., M. Zorec, J. Mrázek, Y. Kobayashi, and R. MarinšekLogar. 2003. Butyrivibrio hungatei sp. nov. and Pseudobutyrivibrio xylanivorans sp. nov., butyrate-producing bacteria from the rumen. Int. J. Syst. Evol. Microbiol. 53:201209.

Koppová, I., F. Lukáš, and J. Kopečný. 2006. Effect of fatty acids on growth of conjugated-linoleic-acids-producing bacteria in rumen. Folia Microbiol. 51:291-293.

Krause, D. O., R. J. Bunch, W. J. M. Smith, and C. S. McSweeney. 1999. Diversity of Ruminococcus strains: a survey of genetic polymorphisms and plant digestibility. J. Appl. Microbiol. 86:487-495.

Krause, D. O., S. E. Denman, R. I. Mackie, M. Morrison, A. L. Rae, G. T. Attwood, and C. S. McSweeney. 2003. Opportunities to improve fiber degradation in the rumen: microbiology, ecology, and genomics. FEMS Microbiol. Rev. 27:663-693.

Mackie, R. I. and I. K. O. Cann. 2005. A review of gastrointestinal microbiology with special emphasis on molecular microbial ecology approaches. In: Applications of Gene-based Technologies for Improving Animal Production and Health in Developing Countries (Ed. H. P. S. Makkar and G. J. Viljoen). Springer, Netherlands. pp. 175-198.

Moon, C. D., D. M. Pacheco, W. J. Kelly, S. C. Leahy, D. Li, J. Kopečný, and G. T. Attwood. 2008. Reclassification of Clostridium proteoclasticum as Butyrivibrio proteoclasticus comb. nov., a butyrateproducing ruminal bacterium. Int. J. Syst. Evol. Microbiol. 58:2041-2045.

Muyzer, G. and K. Smalla. 1998. Application of denaturing gradient gel electrophoresis (DGGE) and temperature gradient gel electrophoresis (TGGE) in microbial ecology. Antonie Van Leeuwenhoek 73:127-141.

Paillard, D., N. McKain, M. T. Rincon, K. J. Shingfield, D. I. Givens, and R. J. Wallace. 2007. Quantification of ruminal Clostridium proteoclasticum by real-time PCR using a molecular beacon approach. J. Appl. Microbiol. 103:12511261.

Pei, C. X., S. Y. Mao, Y. F. Cheng, and W. Y. Zhu. 2010. Diversity, abundance and novel 16S rRNA gene sequences of methanogens in rumen liquid, solid and epithelium fractions of 
Jinnan cattle. Animal 4:20-29.

Polan, C., J. McNeill, and S. Tove. 1964. Biohydrogenation of unsaturated fatty acids by rumen bacteria. J. Bacteriol. 88:1056-1064.

Reuter, H. D., H. P. Koch, and L. D. Lawson. 1996. Therapeutic effects and applications of garlic and its preparations. In: Garlic: The Science and Therapeutic Application of Allium Sativum L and Related Species (Ed. H. P. Koch and L. D. Lawson). Williams \& Wilkins, Baltimore. pp. 135-212.

Schloss, P. D. and J. Handelsman. 2005. Introducing DOTUR, a computer program for defining operational taxonomic units and estimating species richness. Appl. Environ. Microbiol. 71:1501-1506.

Stackebrandt, E. and B. M.Goebel. 1994. Taxonomic note: a place for DNA-DNA reassociation and $16 \mathrm{~S}$ rRNA sequence analysis in the present species definition in bacteriology. Int. J. Syst. Bacteriol. 44:846-849.

Stevenson, D. M. and P. J. Weimer. 2007. Dominance of Prevotella and low abundance of classical ruminal bacterial species in the bovine rumen revealed by relative quantification real-time PCR. Appl. Microbiol. Biotechnol. 75:165-174.
Van Gylswyk, N. O., H. Hippe, and F. A. Rainey. 1996. Pseudobutyrivibrio ruminis gen. nov., sp. nov., a butyrateproducing bacterium from the rumen that closely resembles Butyrivibrio fibrisolvens in phenotype. Int. J. Syst. Bacteriol. 46:559-563.

Wallace, R. J., L. C. Chaudhary, N. McKain, N. R. McEwan, A. J. Richardson, P. E. Vercoe, N. D. Walker, and D. Paillard. 2006. Clostridium proteoclasticum: a ruminal bacterium that forms stearic acid from linoleic acid. FEMS Microbiol. Lett. 265:195-201.

Zhu, Z., S. Mao, and W. Zhu. 2012. Effects of ruminal infusion of garlic oil on fermentation dynamics, fatty acid profile and abundance of bacteria involved in biohydrogenation in rumen of goats. Asian-Aust. J. Anim. Sci. 25:962-970.

Zhu, Z., S. Hang, H. Zhu, S. Zhong, S. Mao, and W. Zhu. 2013. Effects of garlic oil on milk fatty acid profile and lipogenesisrelated gene expression in mammary gland of dairy goats. J. Sci. Food Agric. 93:560-567.

Zoetendal, E. G., A. D. L. Akkermans, and W. M. D. Vos. 1998. Temperature gradient gel electrophoresis analysis of 16S rRNA from human fecal samples reveals stable and host-specific communities of active bacteria. Appl. Environ. Microbiol. 64:3854-3859. 